Research Article

\title{
Relationship between Learning Styles and Academic Performance among Virtual Nursing Students: A Cross-Sectional Study
}

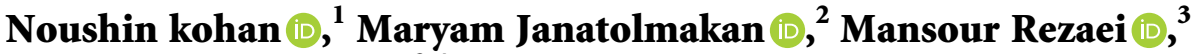 \\ and Alireza Khatony iD $^{3,4}$ \\ ${ }^{1}$ Virtual University of Medical Sciences, Department of Medical Education, Tehran, Iran \\ ${ }^{2}$ Clinical Research Development Center, Imam Reza Hospital, Kermanshah University of Medical Sciences, Kermanshah, Iran \\ ${ }^{3}$ Social Development and Health Promotion Research Center, Health Institute, Kermanshah University of Medical Sciences, \\ Kermanshah, Iran \\ ${ }^{4}$ Infectious Diseases Research Center, Kermanshah University of Medical Sciences, Kermanshah, Iran
}

Correspondence should be addressed to Alireza Khatony; akhatony@gmail.com

Received 16 June 2021; Revised 23 August 2021; Accepted 26 August 2021; Published 6 September 2021

Academic Editor: Ehsan Namaziandost

Copyright $\odot 2021$ Noushin kohan et al. This is an open access article distributed under the Creative Commons Attribution License, which permits unrestricted use, distribution, and reproduction in any medium, provided the original work is properly cited.

\begin{abstract}
Background. The lack of attention of nursing professors to students' learning styles can cause academic failure. The results of studies on the relationship between students' learning style and academic achievement are contradictory. Therefore, this study was designed to investigate the relationship between VARK learning styles and academic performance among virtual nursing students. Methods. In this cross-sectional study, 237 virtual nursing students were enrolled by the convenience sampling method. The VARK learning styles questionnaire was used for data collection. The basis for determining academic performance was the grade point average(s) (GPA) of the previous semester(s). Students were divided into two groups based on their GPA, including strong $(\mathrm{GPA} \geq 15)$ and weak (GPA $\leq 14.99)$ groups. Results. In both strong and weak groups, most of the subjects were unimodal (with a frequency of $92.9 \%$ and $78.5 \%$, respectively), and the rest were multimodal. The most common learning styles in strong and weak students were kinesthetic (57.1\%) and auditory (37.2\%), respectively. The results of chi-square test did not show statistically significant differences between learning styles and academic performance of strong and weak students. Conclusion. There was no significant relationship between the dominant learning styles and academic performance of strong and weak students. However, nursing professors need to adapt their teaching methods to the students' learning styles. More studies are recommended to shed more light on this area of research.
\end{abstract}

\section{Introduction}

Today, due to the COVID-19 pandemic, the education of nursing students has undergone fundamental changes, and presentation of theoretical courses has changed from the face-to-face method to the Internet-based method $[1,2]$. Internet-based instruction is completely different from the usual face-to-face interaction and requires fundamental changes in the teaching methods as well as the students' learning environment [1].

In the meantime, academic performance is an indicator used to evaluate and compare students $[3,4]$. One of the influential factors involved in academic performance is learning styles [5]. To increase the effectiveness of Internet-based education, it is highly important to know about the students' learning styles [2]. Knowledge of students' learning styles is effective in compiling the online courses effectively, as well as modifying and organizing the teaching-learning process $[2,6]$.

The VARK Questionnaire is a method used to determine the type of learning styles. According to this questionnaire, learning styles include visual (V), auditory (A), reading/ writing (R), and kinesthetic (K) [7]. Visual students learn by watching videotapes, pictures, and diagrams. Auditory students learn by listening to lectures, and reading/writing 
students learn by reading texts and taking summaries. Kinesthetic students learn by touching and manipulating objects $[7,8]$. Based on the VARK model, it is possible for students to use several learning styles [6]. Studies that have examined students' learning styles have reported different results, and the most common learning styles have included kinesthetic $[9,10]$, auditory $[11,12]$, and reading/writing $[13,14]$. Several studies have examined the relationship between learning style and academic performance. The results of some of these studies have shown a significant relationship between these two variables [15-19], but in some other studies, no relationship has been reported [3, 14, 20].

Considering the contradictory results of these studies and the importance of nursing professors' knowledge of virtual students' learning styles, the current study was aimed to determine the relationship between learning styles and academic performance among virtual nursing students in Kermanshah, who have been taught through Internet-based instruction. Since learning ability involves both educators and learners, the results of this study may benefit both groups.

\subsection{Theoretical Background/Model. One of the factors af-} fecting students' learning is the type of their learning style [4]. Learning styles are the methods that people use to acquire knowledge or skills [21]. The VARK model is one of the most popular methods designed by Fleming and Mills (1992) to examine students' learning styles $[12,21]$. This model is a kind of educational approach and learning style. Based on this model, students are divided into one of the following categories based on their abilities: visual style (with good visual function), reading and writing style (with good reading and writing function), listening style (with good auditory function), and kinetic style (with good skill performance) $[11,12]$.

\section{Materials and Methods}

2.1. Study Design. This is a cross-sectional study based on the STROBE reporting guidelines.

2.2. Study Sample. The population of the study consisted of virtual nursing students in the first semester of the academic year 1300-1499 $(N=616)$. Study subjects included undergraduate students in the second and higher semesters. The students were selected by a convenient sampling method. The inclusion criteria were employment in the second semester and above. The sample size was calculated to be 237 students using Cochran's formula, with $95 \%$ confidence and an error of 0.05 .

2.3. Data Collection Tools. Data collection instruments included a demographic form and VARK questionnaire. The demographic form included six questions about age, sex, marital status, residence, semester, study resources, and grade point average(s) (GPA) of the previous semester(s). The VARK questionnaire is an instrument used to determine the type of learning style [22]. The reliability of this questionnaire has been confirmed by Zhu et al. [10]. The internal consistency of the Persian version of this tool has been confirmed by Cronbach's alpha method [12, 23].

The VARK Questionnaire has 16 four-choice questions that are used to identify learners' learning styles. The questions consist of four options, and each question is related to a specific learning style. Students should choose one of the options according to their preference. If one response alone does not express their views, they should choose more responses and leave questions that have never happened to them before. Achieving a higher score in each of learning style is considered to indicate a person's greater desire for that style. If a person acquires equal points in more than one style, his/her learning style is considered "hybrid or multimodal." In each style, the minimum and maximum scores are 0 and 16, respectively. Earning equal points in two styles is considered bimodal. Earning points in three or four styles is equivalent to trimodal and quadmodal styles, respectively. To determine the status of academic performance, the GPA of the previous semester(s) was used, which was completed by self-report method. Students with a GPA above and below 15 were assigned to one of the strong and weak groups, respectively.

2.4. Data Gathering Method. First, the study permit was obtained from the Virtual University of Medical Sciences and presented to the officials of the Kermanshah School of Nursing and Midwifery. Since all students were members of the Telegram social network, it was used for sampling. The questionnaires were then uploaded to the nursing students channel in Telegram. They were asked to complete and submit the questionnaires if they were willing. Data were then fed into SPSS software and analyzed statistically.

2.5. Statistical Analysis. For data analysis, version 18 of SPSS software and descriptive and inferential statistics were used. The research spreadsheet created by Neil Fleming was used to calculate the distribution of learning styles. Chi-square test was used to examine the differences between students' academic performance and learning styles. The level of significance was less than 0.05 .

2.6. Ethics. The study was approved by the Ethics Committee of the Virtual University of Medical Sciences (IR.VUMS.REC.1399.018). The objectives of the study were stated for all participants, and written informed consent was obtained.

\section{Results}

The results showed that $8(57.1 \%)$ subjects in the strong group were aged $>22$ years, $10(71.4 \%)$ were male, and 11 (78.6\%) were single. As for residence, most of the subjects $(78.6 \%, n=11)$ lived in the dormitory. Most of the students $(42.9 \%, n=6)$ were in the fourth semester, and the source of study for $71.4 \%$ of students $(n=10)$ was the professors' slides. The preferred method of virtual education for most students $(64.3 \%, n=9)$ was the synchronous method. In the 
TABLE 1: Demographic characteristics of students.

\begin{tabular}{|c|c|c|c|}
\hline Demographic variables & & - & $N(\%)$ \\
\hline \multirow{6}{*}{ Age (years) } & \multirow{2}{*}{$18-21$} & Strong students & $6(42.9)$ \\
\hline & & Weak students & $102(45.7)$ \\
\hline & \multirow{2}{*}{$\geq 22$} & Strong students & $8(57.1)$ \\
\hline & & Weak students & $121(54.3)$ \\
\hline & \multirow{2}{*}{ Mean (standard deviation) } & Strong students & $23.3(3.7)$ \\
\hline & & Weak students & $22.7(3.6)$ \\
\hline \multirow{4}{*}{ Sex } & \multirow{2}{*}{ Male } & Strong students & $10(71.4)$ \\
\hline & & Weak students & $85(38.1)$ \\
\hline & \multirow{2}{*}{ Female } & Strong students & $4(28.6)$ \\
\hline & & Weak students & $138(61.9)$ \\
\hline \multirow{4}{*}{ Marital status } & \multirow{2}{*}{ Single } & Strong students & $11(78.0)$ \\
\hline & & Weak students & $192(86.1)$ \\
\hline & \multirow{2}{*}{ Married } & Strong students & $3(21.4)$ \\
\hline & & Weak students & $31(13.9)$ \\
\hline \multirow{4}{*}{ Residence } & \multirow{2}{*}{ Dormitory } & Strong students & $11(78.6)$ \\
\hline & & Weak students & $111(49.8)$ \\
\hline & \multirow{2}{*}{ With family } & Strong students & $3(21.4)$ \\
\hline & & Weak students & $112(50.2)$ \\
\hline \multirow{6}{*}{ Study resources } & \multirow{2}{*}{ Professor's slides } & Strong students & $10(71.4)$ \\
\hline & & Weak students & $159(71.3)$ \\
\hline & \multirow{2}{*}{ Booklets and notes of classmates } & Strong students & $3(21.4)$ \\
\hline & & Weak students & $38(17.0)$ \\
\hline & \multirow{2}{*}{ Reference books } & Strong students & $1(7.1)$ \\
\hline & & Weak students & $26(11.7)$ \\
\hline \multirow{6}{*}{ The level of interest in virtual education } & \multirow{2}{*}{ Low } & Strong students & $11(78.6)$ \\
\hline & & Weak students & $94(42.2)$ \\
\hline & \multirow{2}{*}{ Medium } & Strong students & $2(14.3)$ \\
\hline & & Weak students & $97(43.5)$ \\
\hline & \multirow{2}{*}{ High } & Strong students & $1(7.1)$ \\
\hline & & Weak students & $32(14.3)$ \\
\hline \multirow{4}{*}{ Type of distance education preference } & \multirow{2}{*}{ Synchronous } & Strong students & $9(64.3)$ \\
\hline & & Weak students & $63(28.3)$ \\
\hline & \multirow{2}{*}{ Asynchronous } & Strong students & $5(35.7)$ \\
\hline & & Weak students & $160(71.7)$ \\
\hline
\end{tabular}

weak group, however, $121(54.3 \%)$ students were in the age group of $>22$ years, 138 (61.9\%) were female, and 192 $(86.1 \%)$ were single. Most of the students $(15.2 \%, n=34)$ were studying in the seventh semester, and about half of them $(50.2 \%, n=112)$ lived with their families. The study source of most subjects $(71.3 \%, n=159)$ was the professors' slides. The preferred method of virtual education for most students $(71.7 \%, n=160)$ was the asynchronous method (Table 1).

In terms of academic performance, most of the subjects (94.1\%, $n=223)$ were in the weak group. The GPAs of the strong and weak students were $17.2 \pm 1.1$ and $13.9 \pm 0.5$ out of 20 , respectively.

In both groups of strong and weak students, most of the subjects were unimodal (with frequencies of $92.9 \%$ and $78.5 \%$, respectively), and the rest were multimodal. The most common learning styles in the strong and weak students were kinesthetic $(57.1 \%, n=8)$ and auditory $(37.2 \%, n=83)$, respectively. Among the strong group of students, none of the subjects was bimodal and only $7.1 \%(n=1)$ were trimodal (including a mixture of visual, reading/writing, and kinesthetic styles). In the weak group of students, $1.7 \%(n=4)$ were
TABLE 2: Frequency distribution of learning styles among students.

\begin{tabular}{lcc}
\hline Learning styles & & $N(\%)$ \\
\hline \multirow{2}{*}{ Visual } & Strong students & $0(0)$ \\
& Weak students & $14(6.3)$ \\
\hline \multirow{2}{*}{ Auditory } & Strong students & $3(21.4)$ \\
& Weak students & $83(37.2)$ \\
\multirow{2}{*}{ Reading/writing } & Strong students & $2(14.3)$ \\
& Weak students & $11(4.9)$ \\
\hline \multirow{2}{*}{ Kinesthetic } & Strong students & $8(57.1)$ \\
& Weak students & $67(30.0)$ \\
\multirow{2}{*}{ Hybrid (multimodal) } & Strong students & $1(1.1)$ \\
& Weak students & $48(21.5)$ \\
\hline \multirow{2}{*}{ Total } & Strong students & $14(100)$ \\
& Weak students & $223(100)$ \\
\hline
\end{tabular}

trimodal and $19.7 \%(n=44)$ were bimodal, with the highest frequency $7.6 \%(n=17)$ related to the combination of auditory and reading/writing styles (Tables 2 and 3) (Figure 1). No statistically significant difference was found between students' learning styles and academic performance (Table 4). 
TABLE 3: Type and number of learning styles among students.

\begin{tabular}{|c|c|c|c|}
\hline Number of learning styles & Types of learning styles & - & $N(\%)$ \\
\hline Unimodal & - & $\begin{array}{l}\text { Strong students } \\
\text { Weak students }\end{array}$ & $\begin{array}{c}13(92.9) \\
175(78.5)\end{array}$ \\
\hline \multirow{9}{*}{ Bimodal } & Visual + auditory & $\begin{array}{l}\text { Strong students } \\
\text { Weak students }\end{array}$ & $\begin{array}{c}0(0) \\
4(1.8)\end{array}$ \\
\hline & Visual + reading/writing & $\begin{array}{l}\text { Strong students } \\
\text { Weak students }\end{array}$ & $\begin{array}{c}0(0) \\
1(0.4)\end{array}$ \\
\hline & \multirow[t]{2}{*}{ Visual + kinesthetic } & Strong students & $0(0)$ \\
\hline & & $\begin{array}{l}\text { Weak students } \\
\text { Strong students }\end{array}$ & $\begin{array}{l}4(1.8) \\
0(0)\end{array}$ \\
\hline & Auditory + kinesthetic & Weak students & $14(6.3)$ \\
\hline & \multirow{2}{*}{ Verbal + kinesthetic } & Strong students & $0(0)$ \\
\hline & & Weak students & $4(1.8)$ \\
\hline & \multirow{2}{*}{ Auditory + reading/writing } & Strong students & $0(0)$ \\
\hline & & Weak students & $17(7.6)$ \\
\hline \multirow{6}{*}{ Trimodal } & \multirow{2}{*}{ Visual + reading/writing + kinesthetic } & Strong students & $1(7.1)$ \\
\hline & & Weak students & $0(0)$ \\
\hline & \multirow{2}{*}{ Auditory + reading/writing + kinesthetic } & Strong students & $0(0)$ \\
\hline & & Weak students & $1(0.4)$ \\
\hline & \multirow{2}{*}{ Visual + auditory + kinesthetic } & Strong students & $0(0)$ \\
\hline & & Weak students & $3(1.3)$ \\
\hline
\end{tabular}
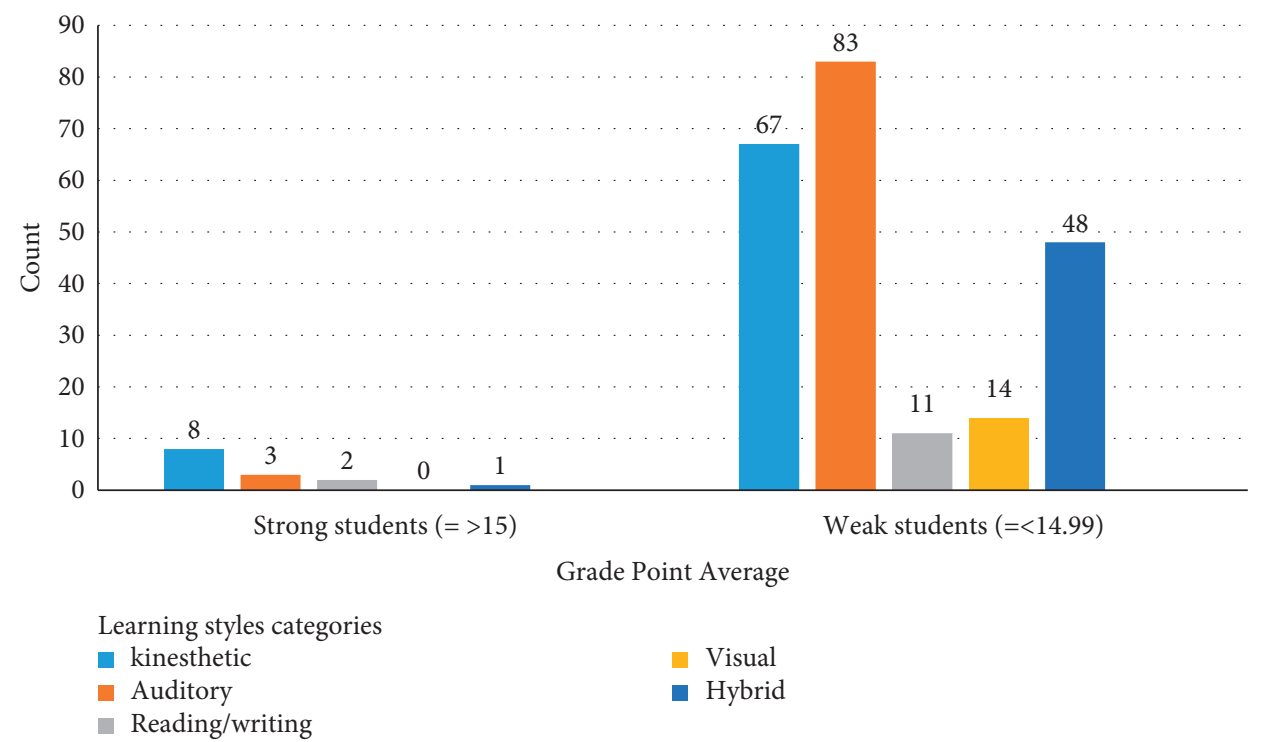

FIGURE 1: Comparison of strong and weak students in terms of type of learning style. The preferred learning styles in strong and weak students were kinesthetic (57.1\%) and auditory (37.2\%), respectively.

TABLE 4: Relationship between the learning styles and academic performance of students.

\begin{tabular}{lccc}
\hline \multirow{2}{*}{ Types of learning styles } & \multicolumn{2}{c}{ Academic performance } & Test result \\
& Strong students, $N(\%)$ & Weak students, $N(\%)$ & Fisher's exact test $P=0.311$ \\
Unimodal & $13(92.9)$ & $48(78.5)$ & \\
Multimodal & $1(7.1)$ & $223(100)$ & \\
Total & $14(100)$ & $223)$ & \\
\hline
\end{tabular}

\section{Discussion}

This study was aimed to determine the relationship between the dominant learning styles of virtual nursing students and their academic performance.
The most common learning style in strong students was kinesthetic, which is consistent with the results of Bangcola in the Philippines and Zhu et al. in China $[9,10]$, but in contrast with the results of Arbabisarjou et al. and Jafari et al. in Iran $[13,14]$. Reading/writing style was the predominant 
learning style in these two studies. The superiority of auditory learning style goes back to the structure of the education system in Iran, in which the predominant teaching style during school and university is lecturing.

On the other hand, students adapt to the teachers' teaching method; therefore, the use of auditory style can be related to the teachers' teaching method [11]. Furthermore, the predominance of teacher-centeredness in nursing education and the unity of teachers strengthen and emphasize the auditory learning style and students' note-taking [24]. It should be noted that the mere use of auditory learning style by nursing students may lead to their illiteracy in the practical and clinical fields. However, nursing professors should consider learning styles of students when choosing their teaching methods.

The preferred learning style in the present study was not consistent with some studies [9-11, 13, 25], which might be related to differences in individual characteristics of research subjects (including experience and motivation) as well as different educational environments.

In the present study, most of the subjects were unimodal in both strong and weak groups. In the strong group, none of them was bimodal and only about $7 \%$ were trimodal (a mixture of visual, reading/writing, and kinesthetic styles). In weak students, less than $2 \%$ were trimodal (a mixture of visual, auditory, and tactile styles), and one-fifth were bimodal, with the highest frequency being a combination of auditory and reading/writing styles. The results of a study in Iranian students showed that the trimodal method was the predominant learning style in students with multimodal learning method. Among students with the trimodal learning method, the most common methods were auditory, reading/writing, and kinesthetic [11]. The results of Mehdipour et al. showed that the most common multimodal learning method in students was the bimodal method [12]. In the study of Behnam et al. in Iran, about one-third of the subjects had a multimodal learning style [26]. The results of Peyman et al. showed that $56 \%$ of the nursing and midwifery students preferred to use the multimodal learning method, and among them, the use of all four learning styles was the most common [27].

The results of the current study are in contrast with the above studies, possibly due to differences in the individual characteristics of the subjects as well as their educational conditions. In this regard, one of the reasons for the prevalence of auditory style or a combination of auditory and kinesthetic styles in the current study may be related to the common teaching method in Iranian universities or the use of various audio-visual aids. However, due to its operational nature, the field of nursing requires teachers who use a variety of active teaching methods such as role-playing, practice and repetition, brainstorming, simulation, and drama to teach students the principles of nursing care [11].

In the current study, no statistically significant difference was found between learning styles and academic performance of students. Our results are consistent with some studies [3,13,14, 20, 22, 28, 29] but contradictory with others $[9,15-19]$. Although, in the present study, there was no relationship between academic performance and learning style nursing professors need to adapt their teaching methods to the students' learning style. In this way, students can be expected to boost their interest in studying and actively attend classes. However, inattention or insufficient attention to students' learning style reduces the effectiveness of teachers' educational activities and students' academic motivation and leads to their academic failure [25].

4.1. Limitations. This study faced two limitations. Due to the data collection method, which was self-reporting, it was not possible to determine the accuracy of the answers, although the anonymity of the questionnaires could reduce this limitation. Another limitation is related to the nature of cross-sectional studies; since in these studies, the variables of exposure and outcome are measured simultaneously, it is not possible to determine the cause-and-effect relationships between them [30], and our study is no exception to this principle.

\section{Conclusion}

Being aware of students' learning style are effective in improving the learning situations, compiling online courses effectively, and improving and organizing the teachinglearning process. The results showed that the dominant learning styles in strong and weak students were kinetic (57.1\%) and auditory (37.2\%), respectively. Furthermore, most students were unimodal in both groups. There was no statistically significant difference between learning style and academic performance. Further studies with different designs are recommended.

\section{Data Availability}

The identified datasets analyzed during the current study are available from the corresponding author on reasonable request.

\section{Conflicts of Interest}

The authors declare there are no conflicts of interest.

\section{Authors' Contributions}

NK, MJ, MR, and AK contributed in designing the study. AK and MJ collected the data, and data were analyzed by MR. The final report and manuscript were written by NK, MJ, $\mathrm{MR}$, and $\mathrm{AK}$. All the authors read and approved the version for submission.

\section{Acknowledgments}

The authors would like to thank all the students who participated in this study. The authors also extend their thanks to the clinical research development center of Imam Reza Hospital affiliated to Kermanshah University of Medical Sciences for their kind support. 


\section{References}

[1] K. H. Morin, "Nursing education after COVID-19: same or different?" Journal of Clinical Nursing, vol. 29, 2020.

[2] D. M. Mupinga, R. T. Nora, and D. C. Yaw, "The learning styles, expectations, and needs of online students," College Teaching, vol. 54, no. 1, pp. 185-189, 2006.

[3] T. H. Almigbal, "Relationship between the learning style preferences of medical students and academic achievement," Saudi Medical Journal, vol. 36, no. 3, pp. 349-355, 2015.

[4] R. Dryer, M. A. Henning, G. A. Tyson, and R. Shaw, "Academic achievement performance of university students with disability: exploring the influence of non-academic factors," International Journal of Disability, Development and Education, vol. 63, no. 4, pp. 419-430, 2016.

[5] Ö. Özyurt and H. Özyurt, "Learning style based individualized adaptive e-learning environments: content analysis of the articles published from 2005 to 2014," Computers in Human Behavior, vol. 52, pp. 349-358, 2015.

[6] M. Ahmadi and A. Allami, "Comparison of health workers learning styles based on vark and Kolbs' questionnaires and their relationship with educational achievement," Research in medical education, vol. 6, no. 1, pp. 19-28, 2014.

[7] M. A. Asiry, "Learning styles of dental students," The Saudi Journal for Dental Research, vol. 7, no. 1, pp. 13-17, 2016.

[8] N. Othman and M. H. Amiruddin, "Different perspectives of learning styles from VARK model," Procedia-Social and Behavioral Sciences, vol. 7, pp. 652-660, 2010.

[9] A. A. Bangcola, "Learning styles as predictor of academic performance in the Nursing Department of an Asian University and colleges," International Journal of Learning, Teaching and Educational Research, vol. 15, no. 4, 2016.

[10] H. r. Zhu, H. Zeng, H. Zhang et al., "The preferred learning styles utilizing VARK among nursing students with bachelor degrees and associate degrees in China," Acta Paulista de Enfermagem, vol. 31, no. 2, pp. 162-169, 2018.

[11] Z. Jannat Alipour, N. Navvabi, and M. Jahanshahi, "Evaluation of nursing students' learning styles based on VARK learning pattern in ramsar school of nursing \& midwifery," Biannual Journal of Medical Education Education Development Center (edc) Babol University of Medical Sciences, vol. 1, no. 2, pp. 37-45, 2013.

[12] M. Mehdipour, H. Mortazavi, J. Yazdani, M. Namdari, and M. Moradi, "Learning styles of dental students at shahid beheshti university of medical sciences using VARK questionnaire," Iranian Journal of Medical Education, vol. 18, pp. 176-182, 2018.

[13] A. Arbabisarjou, S. Zare, M. Shahrakipour, and G. Ghoreishinia, "The survey of the relationship between the learning style and academic performance in students of Medical Sciences (2016)," Health Sciences, vol. 5, no. 7S, pp. 338-342, 2016.

[14] H. R. Mozaffari, M. Janatolmakan, R. Sharifi, F. Ghandinejad, B. Andayeshgar, and A. Khatony, "The relationship between the VARK learning styles and academic achievement in Dental Students," Advances in Medical Education and Practice, vol. 11, pp. 15-19, 2020.

[15] M. Farajollahi, H. Najafi, K. Nosrati Hashi, and S. Najafiyan, "Relationship between learning styles and academic achievement of university students," Education Strategies in Medical Sciences, vol. 6, no. 2, pp. 83-88, 2013.

[16] M. Komarraju, S. J. Karau, R. R. Schmeck, and A. Avdic, “The big five personality traits, learning styles, and academic achievement," Personality and Individual Differences, vol. 51, no. 4, pp. 472-477, 2011.

[17] Y. S. Li, W. P. Yu, C. F. Liu, S. H. Shieh, and B. H. Yang, "An exploratory study of the relationship between learning styles and academic performance among students in different nursing programs," Contemporary Nurse, vol. 48, no. 2, pp. 229-239, 2014.

[18] Z. Rashidi and M. Moghadami, "The relationship between learning styles with academic achievement and creativity of students senior department of education, psychology and social sciences, Islamic Azad University Roudehen Branch," Journal of Innovation and Creativity in Human Science, vol. 7, no. 2, pp. 1-38, 2017.

[19] S. Ruffing, F. S. Wach, F. M. Spinath, R. Brünken, and J. Karbach, "Learning strategies and general cognitive ability as predictors of gender- specific academic achievement," Frontiers in Psychology, vol. 6, p. 1238, 2015.

[20] S. C. Liew, J. Sidhu, and A. Barua, "The relationship between learning preferences (styles and approaches) and learning outcomes among pre-clinical undergraduate medical students," BMC Medical Education, vol. 15, no. 1, p. 44, 2015.

[21] I. Hussain, "Pedagogical implications of VARK model of learning/imran hussein," Journal of Literature, Languages and Linguistics, vol. 38, pp. 33-37, 2017.

[22] S. Fleming, G. Mckee, and S. Huntley-Moore, "Undergraduate nursing students' learning styles: a longitudinal study," Nurse Education Today, vol. 31, no. 5, pp. 444-449, 2011.

[23] A. Javadinia, G. Sharifzade, M. Abedini, M. Khalesi, and M. Erfaniyan, "Learning styles of medical students in Birjand University of medical sciences according to VARK model," Iranian journal of medical education, vol. 11, no. 6, pp. 584-589, 2012.

[24] H. Karimi Moonaghi, F. Dabbaghi, F. Oskouie, and K. Vehviläinen-Julkunen, "Learning Style in theoretical courses: nursing students' perceptions and experiences," Iranian journal of medical education, vol. 9, no. 1, pp. 41-54, 2009.

[25] S. Jafari and Z. Mollaei, "Mediating role of self-regulated learning strategies for spiritual intelligence and academic achievement," Iranian Journal of Medical Education, vol. 19, pp. 424-432, 2019.

[26] M. M. Behnam, A. Abdollahi, M. Rostaminejad, T. Salehian, and M. A. Behnam, "A study on the learning styles of nursing and midwifery students in Yasuj according to the VARK model (2013)," Armaghan Danesh, vol. 20, no. 3, pp. 243-252, 2015.

[27] H. Peyman, J. Sadeghifar, M. Alizadeh et al., "Learning styles of first year nursing and midwifery students in Ilam University of Medical Sciences," Iranian Journal of Medical Education, vol. 11, no. 9, pp. 1350-1358, 2012.

[28] A. Adera Gebru, S. Ghiyasvandian, and N. Mohammadi, "The relationship between learning style and undergraduate nursing students' academic achievement in school of nursing and midwifery, tehran university of medical sciences, tehran, Iran," American Journal of Nursing Science, vol. 4, no. 4, pp. 147-153, 2015.

[29] M. M. Shahabadi and M. Uplane, "Synchronous and asynchronous e-learning styles and academic performance of e-learners," Procedia - Social and Behavioral Sciences, vol. 176, pp. 129-138, 2015.

[30] R. C. Solem, "Limitation of a cross-sectional study," American Journal of Orthodontics and Dentofacial Orthopedics, vol. 148, no. 2, p. 205, 2015. 